\title{
Cenários, dilemas e caminhos da educação superior europeia
}

\author{
António Magalhães
}

\section{Resumo}

A partir de um exercício de prospectiva efectuado pelo CHEPS, este artigo discute a cartografia dos cenários futuros e dos presentes dilemas do ensino superior (ES) europeu. Trata-se de contribuir para a discussão da gestão política de sistemas massificados, da própria natureza do ES e de fazer assentar a agência dos actores envolvidos numa base que relativiza a assunção de que não há alternativas. $\mathrm{O}$ objectivo não é promover uma grande narrativa que prescreva um caminho privilegiado para o desenvolvimento do ES, mas, antes, identificar posições e contribuir para o debate em torno das escolhas com que este se confronta.

Palavras-chave: Ensino superior. Educação Prospectiva. Políticas do ensino superior.

* Doutor em Sociologia Política da Educação pelo Center for Higher Education Policy Studies, Universidade de Twente, Holanda. Professor da Faculdade de Psicologia e de Ciências da Educação da Universidade do Porto e investigador do Centro de Investigaçáo e Políticas de Ensino Superior (CIPES). 


\section{Introdução}

A partir do exercício de prospectiva efectuado pelo Center for Higher Education Policies Study (CHEPS) (ENDERS et al., 2005a), discuto neste artigo a cartografia dos futuros plausíveis para a educaçáo superior europeia. Com base na combinaçâo do método Delfos e o da escrita de cenários, foram construídos três cenários para o ensino superior e investigaçáo europeus, tendo como horizonte o ano 2020. A crescente assunção do mercado como estrutura e processos de regulaçáo e coordenação da educação superior, a questâo da gestâo política da sua expansão, da qualidade e da avaliaçáo são factores omnipresentes e críticos neste (e noutros) exercício(s). Mas seráo estes cenários de futuros do ensino superior, traçados a partir de tendências e de potenciais de desenvolvimento identificados no presente, destinos inelutáveis? Para além da resposta a esta pergunta, a análise destes cenários permite discutir a própria natureza da educação superior nos actuais contextos e fazer assentar a agência dos actores sociais numa base em que a perspectiva de que Não há alternativa pode ser criticamente relativizada. O objectivo do artigo náo é o de identificar, propor ou defender qualquer nova narrativa mestra que permita uma identificaçáo definitiva de um caminho sociológica e epistemologicamente privilegiado para o desenvolvimento do ensino superior. Trata-se, antes, de cartografar e promover o debate em torno dos dilemas com que este se confronta. O perigo a evitar, no que à agência reflexiva diz respeito, é que os desenvolvimentos da educação superior não fiquem à mercê daquilo que é apenas pragmaticamente possível.

\section{Os futuros do ensino superior europeu}

A prospectiva, ou, na designaçáo que tem vindo a circular nos meios anglo-saxónicos, os estudos dos futuros (Futures studies), é um área cuja epistemologia e metodologia vagueiam entre a arte, a técnica e a ciência. A sua utilização, aos mais diferentes níveis, como técnica de apoio aos processos de tomada de decisão tem vindo a ganhar popularidade em todas as partes do mundo e, principalmente, entre as organizaçóes internacionais. Estes estudos podem ser conduzidos de uma forma científica, mas não são uma ciência no sentido que a modernidade deu a esta palavra, isto é, no sentido de procura de relaçôes constantes entre fenómenos cujo conhecimento permitiria a previsibilidade. Não é, portanto, de surpreender, nem desencorajador para 
a área de estudos, que esta metodologia, em uso há mais de três décadas, não tenha sido muito bem sucedida na previsão dos panoramas actuais.

A prospectiva move-se no âmbito da identificação de futuros possíveis, cabendo aos actores sociais e políticos identificar, em cada um, o desejável, o indesejável e organizar a sua acção em conformidade. Enquanto área de estudo, é ela própria diversa e em conflito. Em conflito no âmbito do seu próprio objectivo e do seu próprio objecto, pois o conhecimento sobre o futuro, pela influência que tem no presente, transforma esse mesmo futuro.

Algumas visões mais instrumentais usam a prospectiva essencialmente como instrumento de gestão e de apoio técnico aos processos de tomada de decisão. Estas visóes, frequentemente, sacrificam convictamente aos deuses do como funciona e à táctica sem estratégia. Outras perspectivas fazem dela um exercício de reflexividade, em que a própria relação entre o possível e o desejável é desconstruída na recusa à tentação de reduzir o desejável ao possível (SANTOS, 1994).

No caso do ensino superior, os futuros desenhados ressentem-se, por um lado, das transformações nos mandatos sociais, económicos e políticos que lhe são endereçados e, por outro, da crescente esquizoidia da sua actual identidade. A ideia de ensino universitário pluralizou-se e está a diversificarse, a diferenciar-se e a segmentar-se entre educação universitária, ensino superior, educação terciária e mesmo pós-secundária (MAGALHÂES, 2004). O declínio da universidade enquanto república de académicos, a emergência da universidade empreendedora, a sua assunção como organização completa (BRUNSSON; SAHLIN-ANDERSSON, 2000), o seu reforço como instrumento dos Estados e das suas políticas ou mesmo os modelos contra-hegemónicos de universidade (e.g. SANTOS; ALMEIDA FILHO, 2008) surgem como desenvolvimentos plausíveis dos actuais sistemas e instituiçôes do ensino superior. De sublinhar que a questão não está apenas na prospectiva, mas sobretudo no papel que a (in)desejabilidade dos futuros, que esta permite identificar, desempenha na agência dos actores sociais. A questão da desejabilidade, superando uma visão da prospectiva de prescrição técnico-normativa, de suspeita neutralidade, deve ser colocada no âmbito da reflexividade social e institucional. Não há, contudo, entre os diversos actores envolvidos, um consenso acerca do que é desejável e/ou indesejável para orientar os caminhos do ensino superior para o futuro e, consequentemente, as tomadas de decisão no presente. 
A OCDE, as Naçóes Unidas, o Banco Mundial e a UNESCO têm levado a efeito estudos de prospectiva, para já náo falar de outros efectuados por outras entidades, designadamente nacionais (e.g. o estudo da Real Academia Sueca de Engenharia, A Universidade do Futuro). O Centro para a Investigação Educacional e Inovação da OCDE identificou quatro cenários (CERI, 2006) que foram apresentados no Fórum do Encontro dos Ministros da Educação da OCDE, na cidade de Atenas, em 2006. De igual modo, as agências das Naçóes Unidas, o Banco Mundial e a OCDE têm vindo a promover abordagens conjuntas nesta área (GEORGHIOU; HARPER, 2008). O próprio Projecto Millennium, da Universidade das Nações Unidas, embora não especificamente dedicado ao ensino superior, promove, implicitamente, a discussão prospectiva deste sector, envolvendo áreas como a dos curricula, da pedagogia, das transformaçóes na localização das instituições de ensino superior, etc. (GEORGHIOU; HARPER, 2008). O propósito deste artigo não é, porém, o de recensear exaustivamente esses trabalhos, mas, antes, o de se colocar reflexivamente entre eles e a atitude a desenvolver face aos próprios futuros identificados.

\section{Cenários e futuros para a educação superior na Europa}

Têm sido, pois, vários os estudos dos futuros desenvolvidos. Por exemplo, a Direção Geral da União Europeia, Unidade de Investigação em Previsão criou, em 2001-2002, um grupo de especialistas (STRATAETAN) para identificar cenários possíveis para o ensino superior, tendo como horizonte temporal 2015. As dimensóes de análise aí assumidas foram a demografia, o consumo estudantil, a identificação de novos actores e de novas funçóes, assim como os impactos prováveis das pressóes da prestação de contas sobre a governação das instituiçóes de ensino superior (STRATA-ETAN EXPEERT GROUP ON FORESIGHT FOR THE DEVELOPMENT OF HIGHTER EDUCATION, 2002). Todavia, tomar-se-á aqui como referência o exercício de prospectiva efectuado pelos investigadores do Center for Higher Education Policy Studies (CHEPS), apresentado em 2004. Por um lado, este exercício parece servir bem o propósito de reflectir, como é desígnio deste trabalho, sobre os dilemas e os caminhos que a educação superior está a trilhar; por outro, apesar de terem sido elaborados com base em pressupostos diferentes, há convergências 
significativas (GEORGHIOU; HARPER, 2008) entre estes cenários e, por exemplo, os resultantes dos exercícios mencionados do CERI/OCDE e do grupo STRATA-ETAN. O que quer dizer que, de certa forma, discutir os cenários do exercício do CHEPS é também discutir os eventuais consensos que dimanam deste e doutros trabalhos de prospectiva para o sector.

Por altura do vigésimo aniversário do Centro, em 2004, foi apresentado um estudo dos futuros do ensino superior europeu sob a designação "o panorama do ensino superior e da investigação europeus em 2020" (ENDERS et al., 2005b, p. 21). ${ }^{1}$ Nos três cenários traçados, é possível identificar a realização daquilo que, no início de 2000, eram diferentes tendências, nomeadamente aquelas que inspiravam e eram inspiradas no Processo de Bolonha. A equipa que protagonizou a pesquisa utilizou o método Delfos e o método dos cenários.

O método Delfos foi desenvolvido a partir da criação de uma rede de comunicação interactiva num painel constituído por 164 especialistas, geograficamente dispersos e em situação de anonimato, no âmbito da qual circularam a informação e os posicionamentos resultantes dos questionários que, em duas rondas, eles preencheram (cf. ENDERS et al., 2005b, p. 1718). O estudo visava responder às perguntas:

Virá a ser implementada uma estrutura de estudos uniforme em todos os sistemas de ensino superior europeu? Virá a ser um Conselho Europeu para a Investigação a mais importante organização para o financiamento da investigação básica? Continuarão os académicos a desempenhar um papel importante na gestâo universitária? (ENDERS et al., 2005b, p. 18).

Baseados nos dados obtidos pelo método Delfos e na sua discussão, os investigadores desenharam cenários para o desenvolvimento do ensino superior na Europa, tendo como horizonte temporal o ano de 2020. No sentido de operacionalizar a necessidade de clarificação entre as percepçóes do que era possível e do que era desejável, o grupo de pesquisa solicitou o desenvolvimento e a escrita de contra-cenários que contrariassem o cenário majoritário, desenhado com base nas respostas dos especialistas no ensino superior europeu. 
Foram construídos três cenários: Centrália, Octávia e Vitis Vinifera. As dimensões que foram tidas em conta na sua elaboração foram de dois tipos. Um primeiro incluía dimensóes como a) o mecanismo de coordenação dominante: Estado versus mercado versus rede; b) a integração e harmonização europeias; c) desenvolvimentos económicos e institucionais; um segundo tipo era referente a dimensóes tidas como sendo exógenas aos diversos cenários e assumidas como mais estáveis: a) demografia: envelhecimento e sensibilidade ambiental da populaçâo europeia; b) economia: ausência de grandes efeitos de recessão ou de $b_{o o m}$; c) o grau de integração da investigação e da educação superior (ENDERS et al., 2005b, p. 21). Os temas cobertos por este exercício foram a educação, a investigação e a inovação, o financiamento, a qualidade, o ensino superior, a sociedade e o mercado de trabalho, assim como a governação e a gestão institucionais.

O cenário Centrália, a Cidade do Sol, caracterizado pela presença forte da coordenação (supra) estatal do ensino superior, por uma igualmente forte integração e harmonização europeias e pela existência de organizaçóes de grande dimensão, foi o que resultou da grande maioria das respostas dadas ao questionário Delfos, e tanto dos juízos de possibilidade como dos de desejabilidade. Curiosamente, contudo, como apontam os investigadores do CHEPS, "na apresentação dos cenários pela Europa, perante audiências constituídas por pessoas com perfis semelhantes aos dos respondentes (alguns foram mesmo respondentes), a maioria mostrou-se claramente a favor do cenário Octávia” (ENDERS et al., 2005b, p. 21). Este tem na sua substância o conceito de rede, dado que aí a coordenação política dos sistemas e das instituiçóes de ensino superior e de investigação feita através de um amplo conjunto de redes globais/multinacionais, locais, interregionais para o desenvolvimento sócio-económico e a inovação. A própria configuração política da Europa, implícita neste cenário, é susceptível de ser traduzida no conceito de Estado-em-rede, com parceiros que vão muito para além do seu espaço geográfico. A universidade, enquanto conceito específico, é mitigada face aos múltiplos e diversos mandatos endereçados ao ensino superior e às suas instituições. Neste cenário, as mãos visíveis e invisíveis do mercado e do Estado jogam o mesmo jogo. Finalmente, o cenário mais minoritário, tanto nas respostas aos questionários Delfos, como para as audiências a que foram apresentados, foi o cenário Vitis Vinifera. As suas características centrais são a coordenação social e política pelo mercado, a prevalência de 
pequenas organizaçóes e um baixo nível de controlo e integração por parte dos níveis superiores dos sistemas.

Um cenário não é uma previsão de como o mundo será a partir de dadas tendências presentes e fenómenos com potencial identificável de desenvolvimento, mas uma descrição de como o mundo seria se alguns dos desenvolvimentos actuais tomassem dadas direcçóes. Entre o possível e o desejável, os diferentes cenários ganham, ou não, plausibilidade na configuração das mudanças e, nestas, surge evidenciado o potencial da acção dos actores sociais. Os cenários, em certo sentido, são tipos-ideais que, partindo de factos ou dos dados actualmente disponíveis, se centram enfaticamente numa dada perspectiva de desenvolvimento para melhor a identificar. $\mathrm{O}$ essencial destes exercícios de prospectiva acaba, então, por ser o presente em mudança e a sua gestão, não devendo ser assumidos como uma reificação do presente no futuro ou como a descrição de futuros reificados. Queiram-no ou não, estes estudos são uma forma de gerir, no presente, a mudança, mediante a identificação da possibilidade e da (in)desejabilidade de alguns desenvolvimentos.

\section{A Cidade do Sol, a Cidade da Teia de Aranha e a Cidade dos Mercadores e dos Microclimas}

Centrália - a Cidade do Sol. Em 2020, Centrália corresponde a uma União Europeia politicamente forte, com uma população envelhecida, mas próspera. As universidades e os centros de investigação públicos, muitos deles resultantes de fusóes, são similares aos actuais, isto é, genericamente, instituiçóes nacionais de ensino e de pesquisa, mas de maiores dimensóes, com enormes campi. Estas instituiçóes cooperam regularmente em associaçóes ou consórcios internacionais, "frequentemente sob a amigável, mas firme, condução de funcionários públicos da União Europeia a partir de Bruxelas" (WESTERHEIJDEN et al., 2005a, p. 63). A homogeneidade do ensino superior reflecte a firmeza de Bruxelas, enquanto a reduzida incerteza espelha o desejo de previsibilidade dos cidadãos. Portanto, pouca diversidade institucional e, pelas características demográficas da população, um ensino superior marcado por uma forte ênfase na aprendizagem ao longo da vida. O ensino superior europeu é caracterizado por uma evidente estratificação, com as mais prestigiadas instituições, do Norte e do Oeste 
europeus, desenvolvendo os cursos de doutoramento e com as do Sul e Este essencialmente envolvidas nos primeiros graus.

No que diz respeito à investigação, em Centrália, desenvolveu-se um pós-Modo $2^{3}$ de produção do conhecimento, dado que as universidades públicas regressaram à investigação básica, assumida como bem público, enquanto as funçóes de I\&D, entretanto separadas daquela, se desenvolvem no âmbito de laboratórios privados, de tipo empresarial, ou resultantes de parcerias público-privado. Uma clara demarcação, portanto, ao nível da investigação, entre público e privado. O objectivo da Estratégia de Lisboa de 2000 de alocar 3\% do orçamento à investigação e inovação, em grande parte devido à forte acção do Conselho Europeu para a Investigação, é atingido em 2012.

No que diz respeito ao governo e à governação dos sistemas e instituiçóes do ensino superior, na Cidade do Sol, estão muito dependentes do nível europeu (o braço firme de Bruxelas!) que garante a coordenação do sector através de normas e regulamentos e do financiamento da investigação e da educação superior. A governação e a gestão das instituiçóes é entregue a administradores e gestores profissionais, mas o controlo das instituiçóes permanece, no essencial, nas mãos dos académicos.

O financiamento do sector continua a ser basicamente público, com base no número de estudantes, sob supervisão supranacional da União Europeia. As propinas, ${ }^{4}$ enquanto fonte privada de financiamento que entretanto se alargou a todos os países europeus, sem serem uniformizadas, são também objecto de regulação pública, no sentido em que os seus limites são fixados pelos governos nacionais. Este cenário é aquele em que há mais barreiras erguidas contra a entrada de fornecedores estrangeiros e privados de educação superior.

Implementada uma estrutura uniforme de graus, $3+2+3$, fundada num mais elaborado European Credit Transfer System (ECTS) aplicado a cursos modulares padronizados, Centrália necessita de um sofisticado sistema de avaliação da qualidade. Um Teste de Competências de Graduados e um sistema de Concursos para a Função Pública da União Europeia são desenvolvidos. Todavia, se a padronização e a difusão de curricula e de materiais de estudo podem ser uma forma de garantir a qualidade do ensino superior europeu, ao mesmo tempo "foi introduzido um enviesamento cultural [...] na medida em que os módulos foram desenhados na sua 
maior parte no Norte e Oeste da Europa" (WESTERHEIJDEN et al., 2005b, p. 101). Por outro lado, existe um sistema de acreditação europeu obrigatório, protagonizado pela Agência Europeia de Acreditação, focado nas competências, enquanto resultados das aprendizagens a adquirir pelos graduados, em detrimento dos inputs e respectivos processos pedagógicos.

\section{Octávia - a Cidade da Teia da Aranha}

Este cenário tem como conceito-chave, como já se disse, as redes, que se tornaram o modo de regulação e de coordenação da educação superior e da investigação na Europa. Ao contrário de Centrália, as universidades mais bem sucedidas são as de pequena dimensão, fundadas nos fluxos de informação e organizadas em redes múltiplas sem centro. Dada a plasticidade das redes, a dimensão das instituiçóes não é padronizada, sendo a sua criação avaliada caso-a-caso em função das necessidades e da missão que perseguem. Algumas delas são o resultado de fusóes com unidades de I\&D de diversa natureza, outras, reorganizadas em torno de agrupamentos disciplinares ou profissionais.

A investigação desloca-se das unidades orgânicas para redes interuniversitárias financiadas pelo Conselho Europeu para a Investigação, pelas agências nacionais e por consórcios empresariais internacionais.

Neste cenário, a diversidade de tipos e de duração dos cursos é maior do que no anterior em consequência dos diferentes e móveis arranjos (inter) institucionais. A variedade de tipos institucionais das organizaçóes de ensino superior é também maior, sobretudo devido à presença e acção, incrementadas pela economia em rede, dos mais diversos parceiros privados. $\mathrm{Na}$ Cidade da Teia da Aranha, é também identificável a estratificação do ensino superior com a assunção da clivagem das instituiçóes do Norte e do Oeste da Europa, consagradas à investigação, e as do Sul e Leste, sobretudo ao ensino. O Modo 2 de produção de conhecimento tornou-se dominante em Octávia e organiza-se em redes públicas, privadas ou públicas-privadas.

O sistema de governação é aqui mais complexo e mais difícil de operacionalizar eficazmente. Trata-se de um modelo de governaçáo de múltiplos níveis, em que o poder e a autoridade se repartem entre actores supranacionais, nacionais e locais, com óbvias dificuldades de coordenação. As redes, sempre em fluxo e recomposição, desviam a ênfase 
nos recursos materiais e humanos para a colocar na gestão dos seus fluxos. Em relação à governação e à gestão, a liderança institucional surge, em termos de relevância, ao lado - senão, por vezes, acima... - das regulaçóes supranacionais e nacionais.

As fontes de financiamento do ensino superior em Octávia são públicas e privadas, pelo que o objectivo da Estratégia de Lisboa de 2000 de alocar 3\% do orçamento à investigação e inovação é atingido em 2009 . O financiamento público destina-se principalmente ao ensino, com a utilização flexível de vouchers no espaço europeu e em diferentes momentos da carreira dos estudantes. "Os estudantes neste cenário são 'protegidos' sobretudo pela multiplicidade de opçóes de acesso que têm mais confiança no grande número de possibilidades de mercado do que na regulação pelo mercado" (WESTERHEIJDEN et al., 2005a, p. 101).

No que se refere ao controlo da qualidade, a Cidade da Teia de Aranha tem o problema acrescido da grande diversidade do seu ensino superior. A falta de coerência derivada da flexibilidade e da descentralização da sua regulação, consequências, por seu turno, dos múltiplos níveis de coordenação política e da multiplicidade e variabilidade das redes, faz com que a certificação do valor dos diplomas passe pela instauração, por parte dos actores sociais ligados ao mundo do trabalho, mormente os empregadores, de exames dos empregados graduados.

\section{Vitis Vinifera - a Cidade dos Mercadores e dos Microclimas}

O terceiro cenário construído foi o da cidade dos Mercadores e dos Microclimas. A União Europeia, enquanto construção política, não sofreu grandes alteraçóes e permanece a tensão entre as soberanias nacionais e as instâncias supranacionais de regulação. A Europa não se tornou, porém, a região do mundo mais competitiva no contexto da globalização económica e da sociedade e economia do conhecimento, tendo mesmo sido ultrapassada pelos Estados Unidos da América e pelo Japão. Os cidadãos europeus estão muito centrados na questão qualidade de vida, no consumo crítico, no lazer etc. $\mathrm{O}$ que quer dizer que a inovação na economia do conhecimento, enquanto vector político, foi equilibrada, e até mesmo superada, pela centralidade dada a estas novas preocupaçóes (FILE et al., 2005). 
Este cenário é aquele em que a diversidade se tornou quase extrema, mas, de uma forma interessante, mais extrema nos contextos nacionais e mais mitigada no espaço europeu. De facto, o aumento em quantidade de parceiros privados encoraja e produz uma grande multiplicidade de tipos institucionais. Aliás, um terço das instituições de ensino superior é privado. A autonomia institucional e a adaptabilidade por ela proporcionada são cruciais e desenvolvem-se no pólo oposto do cenário Centrália. Não se trata tanto de uma simples retirada do Estado da coordenação da educação superior e da investigação, mas, antes, da assunção da regulação pelo mercado (diferente, portanto, daquela que é induzida pelos governos sob a forma de quase-mercados), que premia pelo lucro as instituiçóes mais competitivas. A própria definição e identidade das instituições de educação e investigação são, neste contexto, profundamente reconfiguradas.

No que diz respeito à investigação, o Conselho Europeu para a Investigação, através de um altamente selectivo e concentrado processo e estrutura de financiamento, tornou-se central. A inovação e a investigação aplicada são cruciais, sendo mesmo questionável se há aqui espaço para o Modo $1^{5}$ de produção de conhecimento. Em Vitis Vinifera, a meta dos 3\% do orçamento dedicado à investigação traçada em Lisboa, no ano 2000, é amplamente ultrapassada em 2020, sobretudo devido ao investimento privado em investigação e inovação.

Neste cenário, a governação é ainda mais dominada do que em Octávia pela questáo da liderança institucional, dada a qualidade e a quantidade das relaçóes extra-organizacionais e o peso da competição por estudantes e por financiamento. Sendo o mercado a principal fonte de coordenação política e de regulação social, em Vitis Vinifera os actores do ensino superior e da investigação são essencialmente privados e mantêm relações de tipo empresarial. A educação é vista como uma mercadoria ou produto susceptível de ser vendido e comprado. Este modelo de regulação pelo mercado é sobretudo válido para as formaçóes pós-graduadas, estando a educação não graduada, devido às externalidades que gera, ainda sob coordenação e financiamento estatais. Também no que respeita ao financiamento, este acontece independentemente da natureza pública ou privada da instituição e as propinas variam muito de instituição para instituição.

Neste cenário altamente volátil, disperso e diverso, onde o consumidor é rei, as dificuldades em promover padróes uniformizados 
de avaliação e de comparação, como o ECTS, impostos pelas instâncias de coordenação, são aqui evidentes. A própria ideia de sistemas nacionais de avaliação e de controlo da qualidade deixam de fazer sentido, tendo estes assuntos sido colocados nas mãos da Autoridade Europeia para a Educação e Formação. Esta agência apenas registra os cursos, uma vez que a legitimidade e o valor deles dimana da dinâmica dos mercados em que se posicionam. Porém, entre os cidadãos de Vitis Vinifera cresce a preocupação com a qualidade das instituiçóes de ensino superior. De facto, existem neste cenário instituiçóes sociais que pugnam por uma cidadania critica e responsável, eventualmente como contrapeso e resistência aos excessos da regulação através do mercado.

\section{Os cenários como gestão da mudança}

As diferenças entre as cidades acabam por enfatizar aquilo que, embora com matizados, possuem em comum. Todos os cenários assumem o declínio dos Estados-nação em termos de regulação económica e de coordenação política, em favor de instâncias europeias e globais. Pressupóem o potencial competitivo e de oportunidades de desenvolvimento para os Estados, para a Europa e, por excelência, para as instituiçóes de ensino superior de uma economia fundada no conhecimento e na inovaçáo. Igualmente, nos três cenários, perpassa a assunção de que as universidades, e o ensino superior em geral, se têm de posicionar face ao meio ambiente económico hegemonizado pelo capitalismo flexível e pelo "capitalismo académico" (SLAUGHTER; LESLIE, 1997), bem como face ao modelo organizacional da universidade designado por Burton Clark (1998) "universidades empreendedoras". Dá-se também como adquirido que essa reconfiguração dos modelos organizacionais induz, e tem implícito, sistemas e modelos de governação institucional importados do sector privado e da sua gestão, ou, no máximo, uma tensão de poderes entre os profissionais académicos e os profissionais da gestão.

Estes cenários, porém, sendo possíveis, não são necessariamente o futuro do ensino superior europeu. De facto, são projecções de tendências actuais que não se excluem entre si, nem no presente, nem no futuro. Nesse sentido, são mais importantes pelo potencial analítico do presente que veiculam do que como previsão. Entre a prospectiva e o futuro da educação 
superior surgem, portanto, um conjunto de actualidades, de presentes naturalizados, que é necessário analisar de uma forma crítica.

\section{A reconfiguração do ensino superior entre o possível e o desejável}

Nos três cenários do CHEPS a influência do neoliberalismo e o europeísmo, por exemplo, são dados como inquestionado pano-de-fundo. Nesse sentido, os exercícios normativos de prospectiva, que projectam e legitimam tendências actuais, distinguem-se da construção de guióes para a acção e intervenção reflexivas no campo da educação superior.

Devido ao seu potencial prospectivo, os trabalhos sobre o conceito de educação superior e sobre a transformação dos modos de produção, distribuição e de consumo do conhecimento de autores como Ronald Barnett, Peter Scott, Helga Nowotny, Michael Gibbons, entre outros, poderiam ser indicados como inspiradores deste tipo de perspectivas. A abordagem assumida por Boaventura de Sousa Santos (1994), quer nas suas "teses para uma universidade pós moderna", quer nas suas reflexôes sobre a Universidade do Século XXI (SANTOS; ALMEIDA FILHO, 2008, p. 16), surge, neste contexto, como exemplar e significativa. Santos e Almeida Filho (2008, p. 41) procuram aí identificar e justificar "os princípios básicos de uma reforma democrática e emancipatória da universidade pública", surgindo os futuros e a sua construção sob a forma de guióes fundadores de uma agência social que pressupóe princípios e valores que fundam a sua desejabilidade. São, desta maneira, também articulados o possível e o utópico, e não só projectadas extensóes plausíveis do presente em futuros meramente possíveis. Para esses autores, "o único modo eficaz e emancipatório de enfrentar a globalização neoliberal é contrapor-lhe uma globalização alternativa, uma globalização contra-hegemónica" (SANTOS; ALMEIDA FILHO, 2008, p. 41).

Não obstante, sendo a construção destes guiôes para o futuro distinta - porque fundados na não redução do desejável ao possível - dos exercícios de escrita dos cenários, estes são importantes para a elaboração daqueles e vice-versa. Dizem Dijkstra et al. que "Já há cenários suficientes para o ensino superior em 2012 ou 2020" e perguntam “o que é que poderão os políticos fazer com eles?” (DIJKSTRA et al., 2005, p. 122). 
Mas não é apenas para os governos e para as instâncias de tomada de decisão em geral que os exercícios de prospectiva podem se constituir como instrumentos de mudança e da sua gestáo, mas para todos os actores sociais envolvidos no campo. Conhecedores dos cenários, da sua plausibilidade, das suas ameaças e das suas oportunidades, que podemos nós, académicos, investigadores e cidadãos em geral fazer com eles, neste contexto em que parece ser a própria identidade da educação superior que está em crise e em causa?

\section{As narrativas e os caminhos do ensino superior}

Se até meados do século XX, a educação superior na Europa era, de forma muito consensual, sinónimo de educação universitária, a partir de então, a sua identidade multiplicou-se e fragmentou-se. Actualmente, ensino superior e ensino terciário são comuns designaçóes para este nível educativo - veja-se, por exemplo o título dos relatórios da OCDE, Tertiary Education for the knowledge Society, (SANTIAGO et al., 2008) -, abrangendo o ensino universitário, o politécnico, a educação superior articulada com a investigação e a educação superior essencialmente centrada no ensino. É a própria universidade, enquanto conceito e enquanto instituição que se dilui e fragiliza neste processo (MAGALHÁES, 2006). O ressurgimento do debate sobre a ideia de universidade é, em simultâneo, alimentado e alimento da crise de identidade desta. $\mathrm{Na}$ análise de investigadores como Cowen (1996), a universidade está a ser atenuada, ou como Barnett (2000), que diz que a instituição está a ser dissolvida, ou mesmo a desaparecer, como defende Rothblatt (1995). ${ }^{6}$

As causas deste fenómeno não podem evidentemente ser procuradas apenas no âmbito restrito deste sistema, sendo, antes, indissociáveis das transformaçóes que, global, nacional e localmente, estão a acontecer ao nível económico, social e político, assim como na forte presença, principalmente a partir dos anos 1980, do neoliberalismo nas arenas políticas internacionais e nacionais. Ainda que não determinada estritamente por ele, a reconfiguração do ensino superior de massas, da sua gestão política e governação tem que ser entendida no contexto mais amplo da transformação da produção, da distribuição e do consumo, contexto que tem vindo a ser referido sob a designação de pós-industrialismo, e no quadro da mudanças dos padróes 
sociológicos de relação entre os indivíduos, as famílias, os grupos, o Estado e a educação superior.

Ao lado e com os exercícios de identificação de futuros possíveis para a educação superior europeia, é importante confrontar as novas narrativas identitárias da educação superior com aquela que herdámos da modernidade 7 . Sem a pretensão de criar consenso universal, é fundamental que a discussão sobre o que é e o que significa educação superior e identificar um conjunto de ideias-força que permita pensar e olhar criticamente para alguns futuros que, no presente, se vão configurando como inelutáveis.

Há vários presentes convivendo no actual panorama da educação superior europeia que também se perfilam como futuros plausíveis. Olsen, procurando responder à pergunta "Que tipo de universidade para que tipo de sociedade?” (OLSEN, 2007), salienta que a actual dinâmica da educação superior levanta questôes fundamentais relacionadas com o pacto de longo prazo entre a universidade e a sociedade, isto é, questóes ligadas à sua própria legitimidade enquanto instituição. Identifica quatro visóes da e para a universidade europeia que convivem, actualmente, lado a lado: a) a universidade como uma comunidade de académicos governada por regras erigidas sobre valores tidos como permanentes e identificadores da instituiçáo e dos seus membros (procura livre da verdade, racionalidade e pericialidade); b) a universidade como um instrumento dos governos e das agendas políticas nacionais para a mudança; c) a universidade como uma democracia representativa, fundada na representação dos diferentes interesses em presença no seu interior; d) a universidade como uma empresa de serviços inserida em contextos competitivos de mercados (OLSEN, 2007).

Estas visōes do presente, se traduzidas em perspectivas de futuro, podem, nesse passe, legitimar as formas organizacionais e institucionais actuais como se fossem inelutáveis, quer no presente, quer no futuro.

A Comissão Europeia, actor-chave no processo de integração da Europa, embora promova o debate sobre a universidade e o ensino superior, mantém-se no âmbito de uma concepção instrumental tecnológicoeconómica do sector, "consistente com o ethos de reforma internacional neoliberal” (OLSEN, 2007, p. 41). E este posicionamento também coincide com aquele outro em que a universidade surge como um factor central na implementação de políticas orientadas para o mercado e que vêem na 
educação superior e na investigação um factor crucial para a competitividade no mercado global. A crescente influência da Comissáo Europeia sobre o desenvolvimento do Processo de Bolonha, expressa na forma como vem reforçando o modo como acompanha a sua implementação, tem vindo a configurá-lo como instrumento ao serviço da Agenda Lisboa e do objectivo desta de tornar a Europa a região mais competitiva e socialmente coesa do mundo. Os focos organizadores das políticas dimanadas da Comissão para o ensino superior tornaram-se a economia, os mercados e a gestão. Sendo o objectivo da União Europeia, a partir de 2000, o de competir com vantagem na economia global fundada no conhecimento e na inovação, a ênfase foi colocada nas universidades de investigaçáo (versus universidades de ensino) e no diagnosticado défice gestionário das universidades tradicionais.

Neste último aspecto, o da governação e gestão das instituições do ensino superior, o futuro que o diagnóstico do défice gestionário invoca é também já muito presente no actual panorama europeu. Ivar Bleiklie e Maurice Kogan (2007) identificaram, na sua investigação sobre a organização e governação das universidades europeias, a tendência para a instalação de fortes estruturas de gestão a actuar em paralelo, e mesmo sobrepondo-se, às estruturas académicas construídas em torno dos líderes académicos tradicionais (ver também MAGALHÂES; AMARAL, 2007, 2009).

Consequentemente, a reflexão sobre os caminhos que a universidade e o ensino superior na Europa estáo a percorrer, pode promover a agência dos actores envolvidos na sua definição e identidade, designadamente através de um conjunto de ideias-força (MAGALHÂES, 2004, 2006; SANTOS; ALMEIDA FILHO, 2008) que confronte a diversidade e fragmentação que não possuem apenas as virtudes que algum pós-modernismo lhe pretende atribuir.

No final da década de 1990, Ronald Barnett (1997, p. 2-3) identificou três tipos de atitudes de agência social em relação às transformaçóes em curso no ensino superior:

1) Deixe-se as fúrias no seu sono: o ensino superior, que se transformou de sistemas de elite para sistemas de massas, apesar de todas as críticas, continua a funcionar bem. Aceita-se em geral que aquilo que é oferecido é suficiente.

2) Que mil flores floresçam: a bandeira da perspectiva pósmodernista. Pela rejeição de todas as grandes narrativas, diferentes 
e diversos tipos de ensino superior e instituiçóes poderão florescer, rompendo ao mesmo tempo com a cadeia de regulação do Estado e com a ideia-mestra de ensino superior.

3) Formas de vida: as tribos e territórios académicos evoluem para diferentes e incomensuráveis racionalidades e padróes de desenvolvimento. Tornam-se tão diferentes que o seu processo de diversificação jamais se encontra acabado.

Estas três posições inspiram, porém, filosofias passivas no que diz respeito à agência social no âmbito do ensino superior. Sob inspiração da teoria habermassiana da comunicação, Barnett (1997, p. 93) propóe uma atitude activa, argumentando que o ensino superior se deve concentrar na missão de formar seres críticos, ao mesmo tempo que recusa a redução do pensamento crítico às competências críticas do pensamento.

Contudo, é também fundamental estar ciente de que não é possível, nos actuais contextos sociais e políticos, legislar filosoficamente sobre a educação em geral e sobre o ensino superior em particular. E esta consciência não corresponde a adoptar as posiçóes identificadas por Barnett (1997), pois o que aqui se propóe, em primeiro lugar, funda-se numa concepção de estratégia reflexiva no que diz respeito à identidade da educaçáo superior, e, em segundo lugar, mas não menos importante, na consciência de que as relaçôes de poder que estruturam este debate está longe de promover um diálogo entre parceiros em situação de igualdade na comunicação.

É nesta base que o debate pode ter lugar. Não o promover, nem nele participar, é correr o risco de, ao perscrutar os caminhos e os dilemas da educação superior, apenas se legitimarem os seus actuais desenvolvimentos. O debate deve, pois, abranger dimensóes como a) o carácter público da educação superior versus a sua potencial privatização, tanto no sentido de não ser fornecida por instituiçóes financiadas pelo dinheiro público, como no sentido da crescente clientelização dos estudantes e das famílias; b) a transformação da natureza do conhecimento de modo a tornar-se socialmente responsável versus a sua assunção como vantagem competitiva; c) os modos como o conhecimento é produzido, conservado e distribuído nas instituiçốes de ensino superior; d) as formas de governação das instituições e o papel nelas desempenhado pelos académicos e pela tecnoestrutura; e, finalmente, mas de importância crucial, v. as repercussôes das transformaçóes destas dimensóes no que se pode entender por educação 
superior dos cidadãos, isto é, na vida interna das instituiçóes de ensino superior.

De facto, e porque a educação é uma função e trave-mestra do ensino superior, o debate não pode descurar a crescente pressão sobre as instituições para que estas traduzam, em termos educativos, os seus processos em resultados e, sobremaneira, em resultados de aprendizagem.

$\mathrm{Na}$ educação universitária, a questão da investigação é essencial para a sua dimensão formativa e não uma alternativa a esta. Em vez da diluição da Bildung em competências traduzíveis em resultados da aprendizagem fixados a priori (ou seja, naquilo que se espera que o estudante possua e demonstre no final de um módulo, unidade curricular ou curso) é necessário discuti-la e reinventá-la nos actuais contextos da educação superior e, sobretudo, da educação universitária. $\mathrm{O}$ relevo legítimo dado à formação de pessoas com competências para circular no mercado de emprego altamente flexível e volátil da sociedade e da economia do conhecimento não pode querer dizer a redução da educação superior a projectos de formação de eus empregáveis. No mesmo sentido, a assunção da transdisciplinaridade como uma das características centrais do actual desenvolvimento do conhecimento, não legitima a desvalorização, enfraquecimento ou mesmo o desaparecimento de áreas de conhecimento ou das disciplinas clássicas. Sob a justificação da irrelevância social, muita da relevância da crítica por elas produzida e veiculada pode ser, desse modo, desvalorizada ou neutralizada.

\section{Conclusão}

A reflexão sobre os caminhos e dilemas de desenvolvimento do ensino superior é uma forma ou instrumento de gestão da mudança neste sector. A generalidade dos investigadores do ensino superior reconhece que estấo a acontecer importantes reconfiguraçóes no âmbito da sua expansão e da sua crescente centralidade social e política. A crise de identidade da universidade prende-se com a sua perda de legitimidade e hegemonia sociais (SANTOS, 1994; SANTOS; ALMEIDA FILHO, 2008): a transformação da liberdade académica em autonomia institucional; a transformação dos modos colegiais de governação das instituiçóes de ensino superior, sobretudo das universidades, através da importação de modos de governaçáo e de gestão do sector privado e da consequente distinçáo e clivagem entre liderança 
académica e liderança gestionária; a segmentação e a separação entre ensino/formação e investigação; a transferência dos juízos e dos critérios de qualidade para fora do âmbito da academia e a sua entrega a novos actores e instituiçôes; a transformação dos modos de financiamento, que, no mínimo, passam a conter, ou visam-no como uma meta a alcançar, uma importante parcela vinda do sector privado e/ou de receitas próprias; finalmente, mas longe de ser o menos importante, as transformaçóes no modo como todas estas mudanças articulam, em contextos de ensino superior massificado, os problemas de equidade no acesso (e sucesso) dos cidadãos ao ensino superior.

As estratégias reflexivas não podem, evidentemente, hoje, dada a diversidade de actores e a incomensurabilidade dos projectos em presença, assumir a forma de um programa pormenorizado e, por maioria de razão, universal. Não é essa a proposta que deve resultar da análise feita neste artigo. Trata-se apenas (e isso já não é pouco...) de inspirar uma vigilância contínua e uma atitude crítica em relação aos diferentes discursos, pressões e dilemas com que o ensino superior actualmente se confronta. Como diz Barnett (2004), comentando os discursos sobre a dissolução da universidade enquanto instituição central da educação superior, é importante continuar a reclamá-la e a agenciar as suas transformaçóes na relação entre o que é possível e o que é desejável, numa dimensão crítica que não assuma nem os presentes nem os futuros como destinos inelutáveis:

O que está a emergir é, porventura, uma promessa de uma 'universidade autêntica'. A autenticidade torna-se possível precisamente onde a autenticidade é ameaçada [...]. A conquista da autenticidade é também [...] um conjunto de actos criativos, em que novas pedagogias, novas práticas académicas e novas abordagens da investigação são penosamente desenvolvidas. (BARNETT, 2004, p. 206).

Esta postura, aparentemente mais modesta nos seus desígnios, é crucial para o debate que, como já se disse, ocorre num contexto de desigual distribuição de poder de reclamação e de diálogo. $\mathrm{Na}$ Europa, onde o Processo de Bolonha terá já entrado num período de consolidação, depois da fase mais ou menos administrativa da sua implementação, em cerca de 46 países, esta postura é essencial. Na base das transformaçóes por ele veiculadas estão ingredientes que estão a marcar indelevelmente os sistemas de ensino 
superior europeus, nos seus processos e nas suas estruturas. Cabe-nos a nós, académicos, estudantes, pessoal náo académico e a todos os outros actores da vida externa e interna das instituiçóes de ensino superior envolver-nos no debate activamente e participar nos processos de reconfiguração em curso. Caso contrário, menos do que pensar os caminhos da educação superior, ficaremos confinados a um presente meramente possível.

\section{Notas}

1 O CHEPS tinha também já estado, uns anos antes, envolvido num exercício de construção de cenários para o ensino superior (HUISMAN; DE BOER; WESTERHEIJDEN, 2001).

2 A assunção desta dimensão como permanente foi abertamente colocada em causa pelo surgimento e desenvolvimento da presente crise financeira e económica. Não obstante, enquanto assunção, não prejudica, a meu ver, o exercício, sendo mesmo, dada a (im) previsibilidade do fenómeno, relevante para o argumento aqui desenvolvido.

3 Modo 1 e Modo 2 são termos que pretendem dar conta da transformação nos modos de produção de conhecimento (GIBBONS et al., 1994, p. 3). "[...] no Modo 1 os problemas são estabelecidos e resolvidos num contexto de uma comunidade específica, em grande parte académica. Em contraste, o conhecimento do Modo 2 é desenvolvido num contexto de aplicação. O Modo 1 é disciplinar, ao passo que o Modo 2 é transdisciplinar. O Modo 1 caracteriza-se pela homogeneidade, o Modo 2 pela heterogeneidade. Organizacionalmente, o Modo 1 é hierárquico e tende a preservar a sua forma, enquanto que o Modo 2 é mais heterárquico e efémero. Cada um dos modos utiliza um tipo diferente de controlo de qualidade. Em comparaçáo com o Modo 1, o Modo 2 é socialmente mais reflexivo, assim como acaba por prestar mais contas à sociedade. Este último inclui um mais amplo, mais temporário e heterogéneo conjunto de práticos, colaborando em torno de um problema definido num contexto específico e localizado".

4 Taxa referente à mensalidade de um curso.

5 Taxa referente à mensalidade de um curso. 
6 Cowen (1996, p. 251), define atenuação da universidade ao nível do espaço, referindo-se à sua dimensão internacional e à sua conexão com a economia; ao nível financeiro, no sentido da crescente clientelização dos estudantes e das suas famílias; ao nível pedagógico, referindo-se à massificação do ensino superior e ao surgimento dos professores com "desenhadores de instrução"; e ao nível da qualidade, referindo-se ao facto de os académicos estarem a ser tendencialmente substituídos por gestores especializados na formulação de juízos de valor acerca das actividades levadas a cabo nas instituiçóes. Barnett, por seu turno, defende que a universidade se está a dissolver quer como unidade institucional, quer como centro do Conhecimento (com letra maiúscula) por excelência. As instituições estão a dissolver-se em segmentos organizacionais e o Conhecimento em conhecimentos (BARNETT, 2000, p. 18). Finalmente, Rothblatt (1995) fala do "desaparecimento da universidade" no sentido em que as fronteiras desta estariam a diluir-se. As fronteiras externas desaparecem à medida em que as funçóes da universidade são crescentemente simuladas por outras organizaçóes, como a atribuição de graus (que também pode ser levada a cabo por empresas), a investigação (que pode ser - e é levada a cabo em laboratórios não universitários), etc.

7 A metanarrativa da modernidade que é possível encontrar em Hobbes, Locke, Adam Smith, Rousseau, Hegel, Marx, etc., teve os seus equivalentes no que diz respeito às instituiçóes de ensino superior em von Humboldt e no Cardeal Newman, para mencionar apenas estes dois. Assumindo, não obstante, diferentes matizados, os discursos destes autores possuem algo de muito forte em comum: a sua fé moderna no Homem, no Conhecimento (enquanto Ciência, Verdade) e na História. É neste sentido que a fundação narrativa do ensino superior de von Humboldt, de Newman ou do modelo napoleónico são modernas para além das suas diferenças. 


\section{REFERÊNCIAS}

BARNETT, Ronald. Higher education: a critical business. Buckingham: The Society for Research into Higher Education; Open University Press, 1997.

BARNETT, Ronald. Realizing the university in an age of supercomplexity. Buckingham: The Society for Research into Higher Education; Open University Press, 2000.

BARNETT, Ronald. Epilogue. In: WALKER, Melanie; Nixon, Jon. Reclaiming universities from a Runaway World. Buckingham: The Society for Research into Higher Education; Open University, 2004.

BLEIKLIE, Ivar; KOGAN, Maurice. Organization and Governance of Universities. Bath, v. 20, n. 4, p. 477-494, 2007.

BRUNSSON, N.; SAHLIN-ANDERSSON, K. Constructing organizations: the example of public sector reform. Organisation Studies, London, v. 21, n. 4, p. 721-746, 2000.

CENTRE FOR EDUCATIONAL RESEARCH AND INNOVATION (CERI). Four Future Scenarios for Higher Education. OECD, 2006. Disponível em: <http://www.oecd.org/document/8/0,3343, en_2649_35845581_37031944_1_1_1_1,00.html>. Acesso em: 5 jul. 2009.

CLARK, Burton. Creating Entrepreneurial Universities: organizational pathways to transformation. Dordrecht: Springer, 1998.

COWEN, Robert. Performativity, post-modernity and the university. Comparative Education, London, v. 32, n. 2, p. 245-258, 1996.

DIJKSTRA, Frans et al. Scenarios for Policy in a Knowledge Society. In: ENDERS, Jürgen et al. (Org.). The European Higher Education and Research Landscape 2020: scenarios and strategic debates. Enschede: CHEPS, 2005. p. 119-125.

ENDERS, Jürgen et al. (Org.). The European Higher Education and Research Landscape 2020: scenarios and strategic debates. Enschede: CHEPS, 2005a. 
ENDERS, Jürgen et al. Octavia, the Spider-Web City. In: ENDERS, Jürgen et al. (Org.). The European Higher Education and Research Landscape 2020: scenarios and strategic debates. Enschede: CHEPS, 2005b.

FILE, Jon et al. Vitis vinifera, the city of traders and micro-climates. In: ENDERS, Jürgen et al. (Org.). The European Higher Education and Research Landscape 2020: scenarios and strategic debates. Enschede: CHEPS, 2005. p.85-94.

GEORGHIOU, Luke; HARPER, Jennifer C. The Higher Education Sector and its role in research: status and impact of future-oriented technology analysis. In: CAGNIN, Cristiano et al. (Org.). Future-oriented technology analysis: strategic intelligence for an innovative economy. Berlin: Springer, 2008. p. 115-130.

GIBBONS, Michael et al. The new production of knowledge: the dynamics of science and research in contemporary societies. Londres: Sage, 1994. HUISMAN, Jeroen; DE BOER, Harry; WESTERHEIJDEN, Don. De Tuinen van der Het Hoger Onderwijs: scenarios's voor 2010. Enschede: Twente University Press, 2001.

MAGALHÂES, António M. A identidade do ensino superior: política, conhecimento e educação numa época de transição. Lisboa: Fundação Calouste Gulbenkian, 2004.

MAGALHÂES, António M. A identidade do ensino superior: a educação superior e a universidade. Revista Lusófona de Educação, Lisboa, n. 7, p. 13-40, 2006.

MAGALHÂES, António; AMARAL, Alberto. Changing values and norms in the concept of governance in portuguese higher education. Higher Education Policy, Bath, n. 20, p. 315-338, 2007.

MAGALHÃES, António M.; AMARAL, Alberto. Mapping Out Discourses on Higher Education Governance. In: HUISMAN, Jeroen (Org.). International perspectives on the governance of higher education: alternative frameworks for coordination. Londres: Routeledge; Taylor \& Francis, 2009. p. 182-197. 
OLSEN, Johan P. The Institutional Dynamics of the European University. In: MAASSEN, Peter; OLSEN, Johan P. University dynamics and the european integration. Dordrecht: Springer, 2007. p 25-54.

ROTHBLATT, Sheldon. An historical perspective on the university's role in social development. In: DILL, David D.; SPORN, Barbara (Org.). Emerging patterns of social demand and university reform: through a glass darkly. Oxford: Pergamon Press, 1995.

SANTIAGO, Paulo et al. Tertiary education for the knowledge society. Paris: OECD, 2008.

SANTOS, Boaventura de Sousa. Pela mão de Alice: o social e o político na pós-modernidade. Porto: Afrontamento, 1994.

SANTOS, Boaventura de Sousa; ALMEIDA FILHO, Naomar de. A universidade no século XXI: para uma universidade nova. Coimbra: Almedina e CES, 2008.

SLAUGHTER, Sheila; LESLIE, L. Academic capitalism. Baltimore: Johns Hopkins University Press, 1997.

STRATA-ETAN EXPERT GROUP ON FORESIGHT FOR THE DEVELOPMENT OF HIGHER EDUCATION: Research Relations. Higher Education and Research for the ERA: Current Trends and Challenges for the Near Future. 2002.

WESTERHEIJDEN, Don et al. Centralia, the City of the Sun. In: ENDERS, Jürgen et al. (Org.). The European Higher Education and Research Landscape 2020: scenarios and strategic debates. Enschede: CHEPS, 2005a, p. 63-73.

WESTERHEIJDEN, Don. A tale of three cities: highlights and problems of cantralia, octavia and vitis vinifera. In: ENDERS, Jürgen et al. (Org.). The European Higher Education and Research Landscape 2020: scenarios and strategic debates. Enschede: CHEPS, 2005b, p. 95-101. 


\section{Scenarios, dilemmas and the future of european higher education}

\section{Abstract}

On the basis of a futures study made by CHEPS, this paper discusses the maps of the scenarios of the future and the present dilemmas of European higher education (HE). The analysis of the scenarios focuses on the political governance of mass $\mathrm{HE}$, the meanings of $\mathrm{HE}$ itself and encourages a critical approach to the assumption that there is no alternative. The goal it is not to identify a grand-narrative promoting a privileged solution for the development of $\mathrm{HE}$, but rather to map out positions and to contribute to the debate about the choices that $\mathrm{HE}$ is being confronted to.

Keywords: Higher education. Futures studies. Higher education policies.

\section{Escenarios, dilemas y caminos de la educación superior europea}

\section{Resumen}

A partir de un ejercicio de prospectiva llevado a cabo por CHEPS, este artículo discute el mapeo de los escenarios futuros y de los dilemas actuales de la educación superior (ES) en Europa. Se trata de contribuir a la discusión de sistemas de gestión política de sistemas masivos, de la propia naturaleza de la ES y encoraja un abordaje crítico que relativiza el supuesto de que no hay alternativas. El objetivo nos es promover una gran narrativa que establece una vía privilegiada para el desarrollo de la ES, sino más bien identificar posiciones y contribuir al debate sobre las opciones que se enfrenta.

Palabras-clave: Educación superior. Estudios Futuros. Políticas para educación superior.

\section{António Magalhães}

Faculdade de Psicologia e de Ciências da Educaçáo

Rua Alfredo Allen, Porto, código postal 4200-135

Fone: (+351) 226079700

E-mail: antonio@fpce.up.pt

Recebido em: 7/4/2011

Versão final recebida em: 23/10/2011

Aprovado em: 31/10/2011 